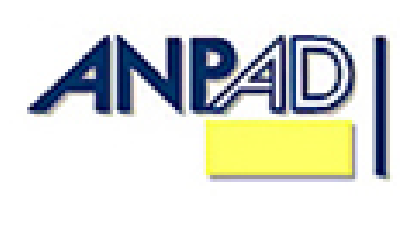

Available online at http://www.anpad.org.br/bar

BAR, Curitiba, v. 8, n. 3, art. 2, pp. 247-265, July/Sept. 2011

\title{
Fostering Linkages between Transnational Corporations and Small to Medium-Sized Enterprises in Brazil ${ }^{(1)}$
}

Delane Botelho *

E-mail address: delane.botelho@fgv.br

Fundação Getúlio Vargas - FGV/EAESP

São Paulo, SP, Brazil.

Milber Fernandes Morais Bourguignon

E-mail address: milber@bndes.gov.br

Fundação Getúlio Vargas - FGV/EBAPE

Rio de Janeiro, RJ, Brazil.

* Corresponding author: Delane Botelho

Rua Itapeva, 474 / 907, São Paulo, SP, 01332-000, Brazil.

Copyright (C) 2011 Brazilian Administration Review. All rights reserved, including rights for translation. Parts of this work may be quoted without prior knowledge on the condition that the source is identified. 


\begin{abstract}
When large Transnational Corporations (TNCs) enter a host country, consequent development of local Small and Medium Enterprises (SMEs) is expected. The public sector may play an important role by fostering Business Linkages (BL), by which TNCs establish purchasing relationships with local SMEs. This article was motivated by growing attention in literature to the interaction between economic development and the ability of companies to absorb and disseminate competences. Its purpose is to understand the role of public policy programs that promote BLs for development by: (a) analyzing actions and programs developed by public and private institutions to foster BL in Brazil; (b) discovering the participants' benefits from such actions and programs; and (c) identifying opportunities for public sector promotion of BL. The research design was a multiple case study which analyzed Supplier Development Projects in five Brazilian states. Results indicate that public policies may complement overall development as well as industrial policy, which is related to capacity building, stimulating technology transfer, and, more broadly, promoting a business friendly environment able to attract investment for development, calling for a regional and sub-regional approach for a country the size of Brazil.
\end{abstract}

Key words: business linkages; transnational corporations; small and medium enterprises; regional development. 


\section{Introduction}

\section{Fostering TNC-SME linkages in Brazil}

What can a host country expect from foreign corporations entering their market? Effects such as increased employment and exports are certainly important, but the development of domestic industries, transfer of technological and management expertise and sustained economic growth are among the foremost expectations. Social and economic development depends on several aspects, such as investments from both the private and the public sector in education, health, safety, infrastructure, and technological innovation. Private companies, whether large Transnational Corporations (TNCs) or local Small and Medium Enterprises (SMEs), play an important role. However, merely having companies set up in a given area is not enough to foster development. A TNC, for instance, may be attracted to a developing country due to tax incentives, lower labor costs and easy access to natural resources only, but import qualified labor and buy from non-local suppliers while barely contributing to regional development.

Promoting and tightening relationships between large companies, whether TNCs or not, and generally small local suppliers located in less developed areas may trigger regional development. The public sector may play an important role by fostering such Business Linkages (BL), by which TNCs establish a purchase relationship with local SMEs in the country where the TNC, or its affiliates, is established (Giroud, 2006). BL are non-equity based relationships between foreign affiliates and domestic firms that have the potential for spillovers (externalities that arise when the entry or presence of foreign affiliates leads to improvements in the capacity, productivity or efficiency of domestic firms by transferring, for instance, technology and managerial expertise). Through BL, SMEs benefit from the accelerated technology transfer, increase in business volume and greater commercial stability, while TNCs take advantage of lower production and distribution costs, a decrease in fixed assets, flexibility in their supply chain and a greater ability to deliver on time (Jenkins, Akhalkatsi, Roberts, \& Gardiner, 2007).

This article was motivated by the growing attention in literature (Ivarsson \& Alvstam, 2004) to the interaction between the level of economic development and the ability of companies and countries to absorb and disseminate competences. As BLs may promote local development, they may be of interest from the perspective of the Federal government as an agent of economic regulation and social development, especially when suppliers come from well-developed areas or from overseas.

The purpose of this research an extension of Bourguignon and Botelho (2009), is to understand the role of public policy programs that promote BL in order to foster development by: (a) analyzing actions and programs developed by public and private institutions to foster BL in Brazil; (b) discovering the participants' benefits from such actions and programs; and (c) identifying opportunities for public sector promotion of BL. The article is structured as follows: this introduction presented the purposes and relevance. Next we present the theoretical background, addressing in particular the buyer-supplier relationship, BLs and their fostering, public policies and the Brazilian effort to develop companies. This is followed by the empirical research method and discussion of results. We conclude with implications for public policies and suggestions for further research.

\section{Theory}

A key challenge for economic development often resides in the accumulation of technology and knowledge, and the capability enhancement of local companies in the country. This can be achieved by buying technology externally, by investing in firm's development programs, or by encouraging inter-firm linkages with firms that operate in high value-added activities and demonstrate high resources. In developing countries, TNCs are often perceived as benefiting from firm-specific 
advantages and resources superior to those possessed by locally-owned firms (Dunning \& Lundan, 2008; Fortanier, 2007; Giroud, 2007a; Lall \& Narula, 2004), and TNCs are also key providers of investment.

The value chain is a fundamental concept in this article, since it refers to the set of activities performed by an organization: from the relationship with suppliers, through the production and sale cycles, to the final distribution phase (Bornstein, 2003). Gefferi, Humphrey and Sturgeon (2005) define the value, production or supply chain as the process implemented by a company or a group of companies where technology is combined with labor and material inputs, organized for and oriented towards a given market, and then distributed. According to the value chain theory, and from the perspective of buyer companies, improvements to the chain performance are expected to be possible only when long-term commitments are established with their key suppliers (Krause, Handfield, \& Tyler, 2007). TNCs generally have highly demanding consumers in regards to quality and process control, because they participate in the world's most competitive environments (Shen, 2008). Thus, they come to place demands and pressure backwards through the value chain. Such companies aim to reduce the number of suppliers and increase their efficiency; SMEs are not always prepared to meet their demands.

Another fundamental perspective in this article is the inter-firm network perspective: networks bringing together partners with complementary competences. Such partnership in this paper is focused on the TNC-SME relationship. With globalization of markets, firms have geographically expanded their activities and, therefore outsourcing, partnerships, alliances and different business arrangements have greatly developed. Markets in this case have no regional borders and firms are specializing in their core business while demanding international contractual relations, either to obtain their inputs or to distribute their products and services. Real networks are being developed, focusing on continuous and sustainable business linkages.

Also, cooperative marketing actions are receiving increasing attention and have been defended by marketing executives and academics. Cooperation may be vertical in a network (between players of technologically distinct stages - e.g.: suppliers and distributors), as well as horizontal, involving competitors and even firms presenting complementary products, with the same target-market. Figure 1 illustrates an inter-firm network, whose key elements are the focal company, suppliers, distribution channels, final consumers, facilitators, other companies/networks and competitors. They all interact to create value to the final customer.

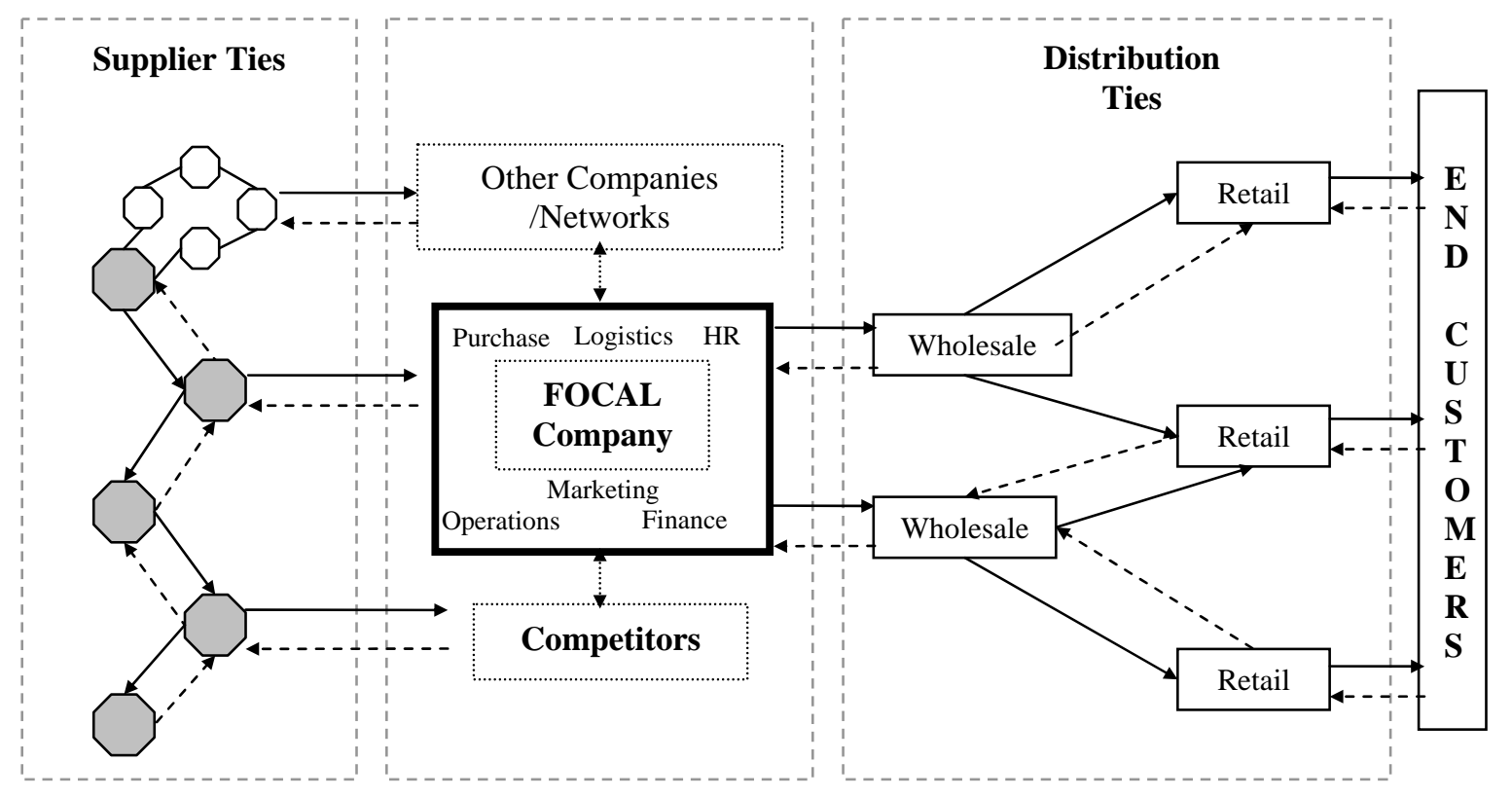

Figure 1. Inter-firm Network.

Source: Neves, M. F., Castro, L. T., \& Consoli, M. A. (2010). Marketing methods to improve company strategy (p. 45). New York. Routledge. 
It is important to focus on the network of partnership members and the links between the members. So, some structural aspects need to be considered when designing the network: (a) the members of the network; (b) the structural dimensions of the network; and (c) the different types of links. The first point assumes that members have some importance for the network. These primary members are usually profit-making units, such as autonomous companies or strategic business units. As shown in Figure 1, the structural dimensions must consider the number of tiers from suppliers to customers, the number of members in each tier and the position of the focal company within the network. When trying to understand and monitor spillovers from the strengthening of BLs, a network perspective is much useful, since the spillover may go beyond a more linear value chain model.

Indeed, BLs may be horizontal, between competitors; collaborative, with national partners for strategic, technologic or managerial purposes; or vertical, with suppliers, agents or domestic clients, including licensing and franchising agreements. Foreign affiliates may help domestic suppliers or clients increase their abilities through improvements to the production quality and efficiency standards, as well as by providing support of and resources for procurement, project management, quality control, training, and/or gathering market information. Such vertical linkages can be upstream (with suppliers and subcontractors), which is discussed in depth in this article; downstream (with clients and agents); or of contract nature (with domestic franchising and licensing) (Scott-Kennel, 2007).

There are relevant studies on value chain and inter-firm network in the context of the buyersupplier relationship in developing countries. Kumar and Bergstrom (2008), for instance, analyzed a pattern of a long-term buyer-supplier relationship in South Africa, India, and Pakistan. They concluded that the more developed the buying market was, the better the local supplier was treated by the TNC, and the TNC-supplier relationship was stronger. Jeppesen and Hansen (2004) depicted the standards of management technology transfers from TNCs to their suppliers in developing countries, as divided into three main patterns: (a) identification of standards; (b) control and monitoring; (c) technical collaboration. Such patterns deliver a continuum ranging from low (determination of standards) to high (technical collaboration) interaction between companies. Client companies require products certified by internationally recognized authorities when determining standards, which forces suppliers' technological development. Control and monitoring are under client-imposed standards, and often introduce control mechanisms, such as the Michelin Certificate, which is provided to distributors in Brazil that meet the quality standards required by Michelin. Technical collaboration occurs when large companies offer technical support to their suppliers so that they reach the standards required by the former, usually involving specialized technical staff visiting the supplier, which tightens the relationship between the two companies.

Ivarsson and Alvstam (2004) investigated the technology transfer in emerging countries, obtaining the following results: (a) technology transfer is essentially based on BL, especially in the manufacturing sector (rather than in Research \& Development); (b) the assistance was not the same for each supplier the TNC supported, which proves that such benefits depend on suppliers' initial technological capacity, and their ability to learn and absorb technology; (c) long-term relationships based on trust are important to the collaboration and learning between companies, which brings benefits to suppliers while they improve their technological capacity and explore prospective markets. In general, the private sector in developed countries is responsible for creating and developing Supplier Development Programs (SDPs) and BLs, but in developing countries the public sector is the most important supporter of SDPs and BLs (Shen, 2008).

\section{BLs and their Fostering}

TNCs have a substantial impact when they participate in the economies of developing countries; ranging from affecting the countries' balance of payments, local investment rates and capital stocks, employment levels and local firms' competitiveness (Lall, 2002; Lall \& Narula, 2004; Moran, 2006). For this reason, host governments carefully design policies to first attract foreign firms to operate within their national borders, and second, to try and maximize the positive impacts and spillovers from 
TNCs' presence in their country. TNCs may minimize market imperfections, such as bringing resources that are difficult to find in a specific market, transferring technology, introducing management and labor techniques, and providing access to international production networks and to major markets. Foreign firms have both a direct impact through their activities and an indirect impact through activities that might be generated in the rest of the economy as a result of their operations.

Several kinds of TNCs, depending on the different association of linkages, may deliver different impacts to domestic companies, and development as a whole. Some BL contexts are (Meyer-Stamer, 2006): (a) Local Productive Arrangements (LPAs), groups of companies formed according to their location, delivering high competition and export potential to the group; (b) Value chain development, consisting of spatial aggregates larger than LPAs, where producers are in the same value chain, with several phase changes before project completion. Power relationships can be symmetric (when suppliers and buyers have similar sizes, for example), or asymmetric, when TNCs are related to SMEs, generally with local performance scope, as the case of this research. In the asymmetric case, governance structures become an integral part in relationships, and can be used as an inspection tool for power differences (Meyer-Stamer, 2006).

Fostering BL offers governments some challenges: to promote competition among domestic companies, enhance information exchange and raise awareness about what TNCs require from domestic companies. Mandatory public policies (such as compelling TNCs to buy locally) may be inefficient, as they oppose the free market concept (Giroud \& Botelho, 2008). Thus, governments normally take other actions to attract investors and influence their activities by providing a business/investment friendly environment, in which relationships between companies may be optimized.

\section{Public Policy and the Brazilian Effort to Develop Companies}

Few comprehensive studies focus specifically on government-related linkages policy (apart from Battat, Frank, \& Shen, 1996, and Giroud 2007b, focusing on East Asian economies). Foreign Direct Investment (FDI) friendly policies proliferated in the 1990s, in line with governments' efforts to create attractive policy environments, particularly in the developing world (Lall \& Narula, 2004). Generally, governments develop FDI policies around three key objectives: namely attracting FDI, enhancing positive FDI impact, and addressing foreign investors' concerns to maintain or expand FDI levels. The State government plays an important role in attracting FDI, mainly after recent nationalization of multinational companies in Bolivia in 2006 (oil and gas fields) and in Venezuela in 2007 and 2008 (cement and telecommunications), which reduced companies' trust in investing in countries with high commercial instability and/or high political risk.

It is not only a matter of bringing investment through attracting TNCs, but taking advantage of their role in the overall productive system. For example, TNCs may be important sources of income and development, but their job opportunities are not proportional to their size. In 2008, although 420 of the world's top 500 TNCs had affiliates in Brazil, they accounted for only $2 \%$ of the jobs (Observatório Social, 2005). However, SMEs accounted for 17.2 million legal Brazilian jobs, compared to 8.8 million from large-sized companies (companies with over 500 employees in the industry sector or 100 employees in the service sector) (Serviço Brasileiro de Apoio às Micro e Pequenas Empresas [SEBRAE], 2008).

Most countries have national or local Investment Promotion Agencies (IPAs), not only to attract more foreign investors, but also to focus on creating jobs, exports, and technological transfers related to the flow of such investments. Some Brazilian IPAs include APEX (Brazilian Trade and Investment Promotion Agency, at the federal level), INDI (Minas Gerais Institute of Integrated Development) and INVESTE-São Paulo (Agency for Promotion of Investments and Competition of the State of São Paulo). 
Brazilian governmental actions to attract investments started in the late 1980s and early 1990s, when the country underwent changes to imitate the design of the most developed economies of that time. The country's structure to promote investments is complex, as it is developed by a federal system of institutions, investment promotion agencies, public (state and federal) and private development banks, in addition to non-governmental organizations, as shown in Table 1.

Table 1

Examples of Investment Promotion Agencies (IPAs) in Brazil (or Development Institutions with Investment Promotion Roles)

Brazilian system of institutions

- Brazilian Trade and Investment Promotion Agency (APEX)

- System for the Promotion of Investments and Transfer of Technology to Companies (SIPRI)
IPAs from state development banks

- Goiás Development Funding Agency
(GoiásFomento)
- Rio Grande do Norte Development Funding Agency
(AGN)

Non-profit private organizations

government and private organizations

Pernambuco Economic Development Agency (AD Diper)

Minas Gerais Industrial Development Institute

Rio Grande do Sul Development Agency (Pólo-RS) (INDI)

Source: Giroud, A., \& Botelho, D. (2008, March). Policies promoting MNEs linkages in host economies: a comparison between Brazil and Malaysia (p. 7). Proceedings of the Organisation for Economic Co-operation and Development (OECD) Global Forum of Investment, Paris, France, 7.

The Ministry of Development, Industry and Foreign Trade is the lead agency in charge of coordinating business promotion policies, becoming more important in 2007 with the reinforcement of the Permanent Forum of Micro and Small Companies (originally created in 2000), through the Brazilian Statute for Micro and Small Companies. The Brazilian Constitution provides a differentiated treatment to those companies, enforceable by law, with actions applying to administrative, tax, social security and labor matters.

There are two key Brazilian institutions that seek to foster the improvement of the business environment, and, indirectly, to promote BL: Brazilian Development Bank (BNDES) and Brazilian Micro and Small Business Support Service (SEBRAE). The country makes efforts at fostering micro and SMEs, but it still lacks public policies specifically focused on fostering BL. A study by Almeida, Cretoiu, Mendonça, Rossetti and Resende (2007) mapping the status of BL-related activities in the country did not find any federal public policy specific to them, although policies and programs with other purposes could contribute somehow to generate BL.

Development programs and IPAs, as potential sources of BL, are more efficient than the activities related to only providing financial incentives (Almeida, Cretoiu, Mendonça, Rossetti, \& Resende, 2007), and large companies' demand is not enough to set sustainable BL. Building BL also requires commitment from the relevant companies and the participation of all stakeholders: governments, IPAs, chambers of commerce, development funding banks, business associations, nongovernmental organizations, media, universities, and research institutes.

The overall Brazilian scenario may create opportunities for BLs: the country has a great number of micro and small companies (in 2008 they were $99.2 \%$ of the total number of officially registered companies, responsible for $57.2 \%$ of total jobs and for $26.0 \%$ of the wage bill). The Brazilian environment is attractive to international companies as well: it has offered a period of economic stability, when compared to the last two decades, with inward FDI reaching US\$ 45.1 billion in 2008, 
the highest amount since Brazil began keeping records in 1947 (Banco Central do Brasil, 2010). Also, there is no difference in treatment of foreign companies, from a legal standpoint, in all matters relating to tax, labor rights, social security, or civil and commercial law, which helps to improve the investment climate.

\section{Method}

With the intention of analyzing programs aiming to foster and strengthen BL, the Projeto Vínculos and the main Brazilian SDPs, as described below, served as references. Projeto Vínculos was chosen for its purpose of creating, fostering and developing BLs in the least developed regions in Brazil, i.e., the North and Northeast, and reinforcing SMEs towards regional development, by increasing the local production capacity and the domestic business sector efficiency. SDPs were considered because their main purpose is to speed up regional growth with the participation of local companies in large TNC investments (also named anchor companies in these programs), mainly from base industries, such as mining, pulp and paper.

Projeto Vínculos was created in 2004 as the result of collaboration between the German Cooperation for Development (GTZ), United Nations Conference on Trade and Development (UNCTAD), Ethos Institute, Fundação Dom Cabral and SEBRAE. It comprises a managing committee aimed at getting companies, professional associations, and organizations able to make sustainable BL in a certain region. This committee takes the strategic decisions and guides the actions taken by Projeto Vínculos, determining where to act and the number of participating companies, for example.

SDPs have a different structure, in that the TNCs or the local government mostly take the initiative to promote the linkage. In the SDP of the northeast state of Maranhão, the state government stepped in to apply the methodology, while in the SDP of the northern state of Pará, a TNC was the one pulling the trigger. Analyzing SDP and Projeto Vínculos allows evaluating the public authority performance when it comes to participating in BL programs.

The research design was a multiple case study, since the study subject, BL programs, offer more than one case to be studied (Yin, 2005). We conducted several research trips and nineteen interviews with experts from different organizations in Brazil and in Europe to endorse the analysis. Key representatives of the following organizations were interviewed from May, 2007, to July, 2008: IPAs, to comprehend how the development funding agencies work and the extent of their relationship with the public authorities; institutions that promote BLs, including industry associations of eight states, Projeto Vínculos (states of Pernambuco, Bahia, Ceará, Amazonas and São Paulo), consulting firms, and representatives of SDPs in four states; representatives of the state and federal government, including the Ministry of Development, Industry and Foreign Trade, as well as APEX; managers from TNCs and SMEs; representatives of the United Nations Conference on Trade and Development (UNCTAD).

On average, each interview lasted 45 minutes. All the interviews were recorded and their contents were carefully analyzed following the structure suggested by Nogueira (2001). The interview protocol, as showed in the Appendix 1, had categories and subcategories, mostly based on Gefferi et al. (2005), so answers could be categorized. Nevertheless, new dimensions were raised from interview to interview and therefore some new categories emerged.

We employed the theoretical structure proposed by Gefferi et al. (2005) to analyze the relationship between companies and it was also the basis for the development of the interview protocol and its categories. Their theory classifies the purchase and sale relationship standards under three variables: (a) information complexity levels: information required throughout the value chain, especially concerning production process specifications; (b) codification ability: whether the 
information about a specific transaction can be coded, decoded, and transmitted at low costs (depending not only on the information complexity, but also on the companies' effort to code such information); (c) suppliers' capacity: whether suppliers are able to meet the requirements dictated by TNCs in their transactions. The following categories were used: program history; products; technology standards classification; training and standards for technology transfer program benefits; the state government role; spillovers identification; the program membership and its potential issues.

Each category and subcategory had a group of speeches that was cross-analyzed in order to allow researchers to draw conclusions and suggest public policies for governments to work with BLs towards generating local development.

\section{Discussion}

We deeply analyzed two successful SDPs in Brazil: the SDP of the state of Maranhão and the SDP of the state of Pará. Three Projeto Vínculos sub-programs were also analyzed: a supplier training program in Bahia, Projeto Vínculos Pernambuco and Projeto Vínculos Ceará. The 'Programa Desenvolvimento de Fornecedores do Maranhão' (the Supplier Development Program of Maranhão) started in 1999, with 78 companies participating. Now it has almost 400 active companies in sectors including manufacturing, construction, engineering, automation and services. The program was created by the state government, in association with the commercial and industrial associations and SEBRAE, but Vale (second largest global producer of manganese and iron alloys) and Alumar (consortium of the four big aluminium producers) are the leaders of the program. The program aims to provide technical and management assistance to SME suppliers, and, as consequence, to promote their development.

With specific certifications, some suppliers are entering in new markets both domestically and abroad. The 'Programa Desenvolvimento de Fornecedores do Pará' (Supplier Development Program of Pará) is coordinated by the industry association at the state level in partnership with the state government, CVRD, and business associations. With more than 1,000 companies enrolled, this program has the characteristics of being regional, multi-sector and not belonging to any private company. The funding comes from ten large companies, seven of them in the mining sector. Technical support is provided by BDS (Business Development Services) providers, such as SEBRAE, National Industrial Training Service (SENAI) and Social Service of Industry (SESI).

Projeto Vínculos comprises a steering committee aimed at getting companies, professional associations, and organizations able to build sustainable BLs, mainly in the north and northeast regions of Brazil. A partnership between Projeto Vínculos and the supplier training program in the state of Bahia was initially created, after their organizers understood both programs had common purposes. The partnership was guaranteed by the injection of funds into this SDP, which already had development of a methodology underway, allowing a greater number of companies to participate in the program. The Bahia Program is funded by large companies (anchor companies) and suppliers, with monthly contributions, at a ratio of around $70 \%$ and $30 \%$, respectively. To focus on suppliers' development, each anchor company designated ten suppliers, which strengthened already existing linkages. There is also a restriction on the admission of new suppliers: they are accepted only when new anchors are admitted to the program, or when a supplier reaches the full development cycle, leaving opportunities for other SMEs' development. Similar BL methodology was also applied to Projeto Vínculos in the states of Ceará and Pernambuco.

The SDP of Ceará and Pernambuco of Projeto Vinculos was created from a partnership of companies, public authorities and a specialized consultant. The work model was first applied in 1995, in the state of Espírito Santo, at the request of some TNCs. Several relevant sectors from Espírito Santo were brought together at that time, such as the Trade Union of Companies from the civil 
construction and metallurgy industry. A similar program was developed in the state of Minas Gerais and later deployed to other states.

SDPs (Maranhão and Pará) and Projeto Vínculos have similar purposes: training suppliers to better serve large local companies and strengthen the regional business environment. Moreover, both bring together professional associations and BDS providers, such as SEBRAE and SENAI. The SDP, however, has a structural focus, connected to the base industry, open to every sort of SME willing to participate. Projeto Vínculos is focused on large companies' requirements and their supply needs. They also differ in the methodology applied: SDPs work in three fields: (a) training business professionals, managers and workers; (b) strengthening companies and professional associations; and (c) corporate advisement for businesses. Projeto Vínculos (in Bahia, where it is stronger) benefits from the certification of an outsourced institute, the Institute of Metrology, Standardization and Industrial Quality of the state of Bahia (IBAMETRO). The first evaluation performed with companies analyzes three major matters: (a) basic criteria related to the documents on the tax and economic status of companies; (b) ranking criteria related to business management, quality, environment, health and safety at work, and social responsibility; and (c) the selection criterion is the evaluation of the supplier by the TNC.

Most suppliers in both SDPs and Projeto Vínculos are service providers, supplying products related to the TNCs' internal routines. Therefore, we cannot make inferences about improvements in products delivered into the production chain, but rather about improvements concerning the overall SMEs' capacities and processes. The goal of TNC procurement divisions is not only to obtain highquality products, but also to certify that such products were produced according to a high-quality process.

As far as company relationship and technology transfer standards are concerned, information was proven to be of low complexity, as most transactions refer to routine and maintenance operations. The interviews revealed an environment of low technological complexity for goods manufacture for, and service supply to, anchor companies, although specific technical knowledge and strict safety standards are required. The reliability of information from the programs analyzed may be ranked as both high and low, as some companies already have such ability, while others are less developed. The codification of products and procedures adopted by companies participating in the programs does not involve cutting edge technology. We observed high capacity to perform technical activities, but low managerial ability, which is exactly what is targeted for development according to Projeto Vínculos' and SDPs' goals.

As the complexity of transactions is product specific, complex transactions will only take place in existing companies as new types of transactions are developed. In view of the nature of the goods offered, partnerships in training, management and certifications offered, suppliers are very likely to reach high levels of codification ability.

The technology transfer standards (Jeppesen \& Hansen, 2004) in the programs analyzed were primarily concerned with improvements to management practices and adjustment to minimum management quality requirements, not reaching the production technology level. The cases studied did not present examples of anchor companies' technicians working closely with suppliers. Instead, thirdparty organizations, such as SENAI and SEBRAE, are subcontracted for suppliers undertaking company training. As soon as a new supplier joins the program it is initially assessed, and then undergoes a training process, where it is evaluated under criteria based on the anchor company requirements.

With respect to the BL fostering programs, suppliers have reaped the following benefits: acquisition of management practices and techniques, knowledge of applicable laws and later compliance with them, increase in business volume, easier access to professional associations, strengthening of business ties with neighboring clients and internal training at low costs. In general, SMEs are hardly aware of the current law and certification requirements. Environmental license certificates, which are essential to do business with export companies, were, in some cases, unknown 
or ignored. The programs are an opportunity to provide such knowledge, so that these companies meet legal requirements.

The benefits of BLs mentioned by anchor companies were: increased supplier reliability; longterm supply maintenance (avoiding a constant change of suppliers); a relationship that makes suppliers more knowledgeable about TNCs' requirements and needs; assurance of relationship continuity; and making TNCs more confident about supply stability.

\section{The role of the State Government}

Most interviewees in BL programs were asked about the State role as a promoter of BL. By 2008, Projeto Vínculos had not sealed any partnerships with governmental agencies. SDPs, on the opposite, had a number of actions jointly taken by institutions and public authorities, ranging from institutional and financial support to public sector coordination (in SDP-Maranhão). There was an attempt to analyze successful practices or identify association opportunities between government and programs, potential incentives, and examples in which the presence of government was not welcome. The first challenge to be overcome is the bad image the State has when it comes to its capacity of involvement in typically private issues. For example, when a supplier was asked about the government performance in the BL program, the following answer was given: "government has the role of improving the overall business environment, but it is not skilled to directly manage a program like this, because they lack managerial capabilities”. The possibility of using the program for political purposes, and the consequent shift in focus, is another negative aspect observed in the State: "one of the main grounds of this program is the apolitical aspect, benefiting companies to their growth, and to create jobs and income to the State”.

However, good examples of close relationship with the government were also observed: "the municipal government is one of our partners because our company is installed in the city industrial area, and we have a program for using local labor, bringing suppliers, and we somehow receive tax incentives. There is also an internal training, paid by the company, in partnership with universities and federal, state and municipal institutions". Another positive example of the State was in the interview with SDP-Maranhão. As the anchor company was privatized during the process, the business environment was impacted, and many suppliers were not prepared to face this new reality. After that, companies from other states, especially from the South and Southeast Brazil, with a greater degree of competitive edges, could be setup there. There was enough awareness that a supplier training program had to be created. At that point, the state became a promoter of a process joining the companies, suppliers, buyers, professional associations (created to support and maintain the companies) and the State: "We released the program, identified the demands from these large-sized companies and realized that we had to attack the management issue, with partnerships with the Labor Department, SENAI etc".

Upon the creation of SDP-Espírito Santo, institutional support was more important than financial one. It is presently administered by the Industry and Trade State Department, which delegates important decisions to a managing committee, where the government participates with the program partner companies.

A critical analysis of the role the State Government plays in promoting BL can be based upon a subtle, but very important difference, considering the role of trying to be both a development actor and the facilitator and promoter of local development. This distinction emerges from interviewees speeches on the topic.

As a development facilitator or promoter, the State Government has the fundamental role of first taking care of basic resources such as basic education, training, and infrastructure. Secondly, it provides the legal structure in which business transactions will occur. The government decreases the perceived costs for TNCs of doing business with SMEs by working towards maximizing local resources while reducing the risks and complexities of doing business with local SMEs. 
As a development actor, however, the State Government tries to replicate business functions, such as determining quality standards, assuming technical training or even forming trade groups aimed at marketplace success and support for local SMEs. Very frequently, these types of arrangements fail due to limited managerial resources and expertise, not to mention financial resources. Even organizations such as SEBRAE, SESI and SENAI, which in fact are state funded, should carefully reflect on their strategic orientation with regarding to promote BL.

\section{Identification of spillovers}

Spillovers, considered as direct and indirect benefits from BLs to local economy, were observed in the programs evaluated, although the literature (Girma \& Pisu, 2008) is controversial on how to identify them and their direct relation with BLs. Positive results were observed, for example, in the creation of supplier forums, where SME suppliers meet on a regular basis to discuss common issues, encouraging interaction and competitiveness.

Interestingly, the projects were first conceived as primarily intending to strengthen TNC-SME business links. However, what also happened was the strengthening of SME-SME, TNC-TNC and the access of SMEs to TNCs' other networks. Figure 2 shows the original idea schematically and its spillover effects, from the network perspective.

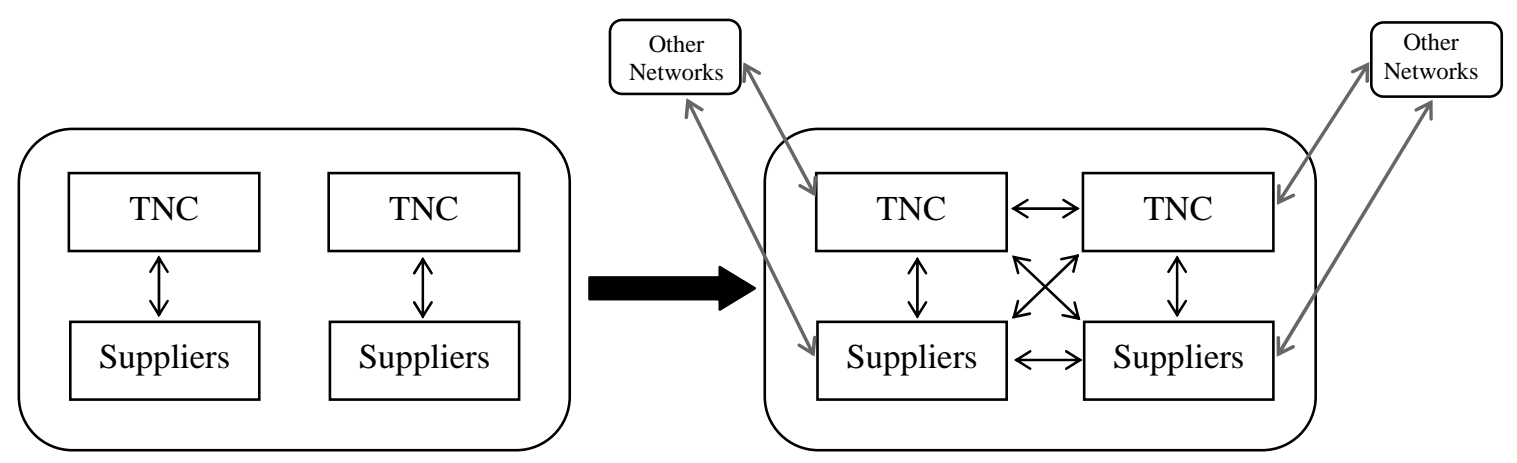

Figure 2. The Spillover Considering the Network Perspective.

Suppliers' admission to the program is not always easy or automatic, although they reap benefits and get training to improve their performance in the market. Companies have cultural factors that influence such admission. In Projeto Vínculos, companies join the program after a phase called engagement. First, anchor companies are engaged and, subsequently, their suppliers are: "the lessons learned in the projects point out that engagement meetings should be held in the anchor companies premises, at their own invitation, as these meetings make clear that it is an opportunity for suppliers to be qualified and meet specific requirements from anchor companies that generate business. Engaging SMEs with large companies is different from doing so in Industry Associations, or in SEBRAE, for example”.

Realizing that information should be shared in several ways is a challenge during the engagement phase. Suppliers may fear the loss of business autonomy, besides having their main internal weaknesses exposed to important business partners. As a preliminary status evaluation is performed at the beginning of the linkage, such weaknesses may be an initial barrier imposed by anchor companies. That can be a negative aspect of the State's role as a direct leader in BL programs, since SMEs' weaknesses may represent evidence for punitive actions, such as fines. Therefore, one of the main aspects for BL programs to succeed is trust, both in the program as a whole, and among participating organizations. 


\section{Final Remarks}

The market does not work perfectly in all the interactions among TNCs and SMEs, especially in developing and transitional economies, so there is an important role for government policies and programs to promote business linkages. In general, such policies should be designed taking into account that competition matters, so that both buyers and suppliers strive for business performance that meets global standards. Also, they must consider all key actors: TNCs, local SMEs, investment promotion institutions and the various providers of technological, educational and training, and financial services, IPAs, BDS providers and business associations.

The strength of the programs analyzed lies in the synergy among companies (TNCs and SMEs), public authorities (such as state development departments), third sector organizations (such as NonGovernmental Organizations), professional associations (such as industry associations), BDS providers (such as SEBRAE) and investment promotion agencies (such as APEX).

Companies with no partnership with the State generally had a negative opinion of public authorities' performance, staying away from BL development programs in which public agencies had their participation disclosed. This perspective generally changes after such partnerships occur. The State often operates by providing financial incentives (land donation, tax incentives etc.), which is harshly criticized in the literature (Almeida et al., 2007; Giroud \& Botelho, 2008), as it seems unfair that powerful TNCs receive public financial incentives, especially in poor regions. Nevertheless, financial incentives from local governments resulted in training and qualification of local labor, which were also included in BL programs, demonstrating that this kind of long-term financial incentive is feasible.

No specific federal policies intended to forge BLs were identified in this research, as they occurred only at state level, such as in some SDPs. The programs developed in partnership with local governments worked properly, which means that while the State is not a key player in BL programs, its participation may bring broader benefits, as well as deeper and more structured impacts in local communities or in society itself. The public sector, therefore, can develop public policies and programs to foster BL, but under the following conditions, as identified in the empirical research (in line with Bourguignon \& Botelho, 2009, the previous phase of this research):

1. Complementary policy: targeted at creating linkages to strengthen local or regional industrial policies. For example, in an attempt to strengthen its industrial basis, the state of Maranhão made use of more than just tax incentives to attract companies. Complementing the industrial policy, a BL-strengthening program was conducted, since without high qualified suppliers production costs would increase and the business environment would be less attractive for TNCs.

2. Educational policy and capacity building: the development of a BL program provides the opportunity for identifying companies' main problems and forming specific groups for each of them, besides promoting the exchange of experience and knowledge among the participating companies, which delivers economies of scale in training and qualification. Sometimes the SMEs do not have technical capabilities, and cannot obtain them in the short term, in order to become suppliers to large companies. But a number of SME competencies cannot be underestimated, such as the strong understanding of the local market. Evidence proves that, in such a case, it would be interesting to promote a collaborative linkage arrangement (such as through a consortium) between the local SMEs and other larger companies. This may be carried out in areas such as civil construction, where local companies may be associated with larger domestic (or even foreign) companies to supply a TNC (e.g. to build a new plant for a TNC). It may represent a long term gain for SMEs, since the learning involves not only innovation and technology, but also good practices in conducting business.

3. Complementary policy for attracting investment: by attracting business to a region, the government must make sure it provides minimum operating conditions, such as a strong base industry and basic 
service provision. Instead of restrictive policies (such as creating criteria to compel large companies to buy from local suppliers), there are alternatives that may encourage companies to participate in BL programs, as an incentive for workforce training and managerial development of suppliers.

4. Incentive for technology transfer: there were no explicit technology transfers in the cases studied. Large companies, and TNCs in particular, may be key players in this transfer, and the State is capable of attracting them through its investment attraction policy. Such technology transfer may occur upon, for example, the outsourcing of TNCs' production phases to local SMEs. The participation of research institutions and universities may also be promoted, intensifying the technology development and knowledge transfer to local companies.

5. Business environment development: the empirical research shows that bringing companies together generates new business opportunities. Even though the programs were mainly intended to foster buyer-supplier linkages, supplier-supplier businesses were also boosted. This is because SMEs are in different stages of production and some may supply goods and services to the others, and subsequently to large companies. Therefore, the State should encourage local dynamics, promoting forums for companies to discuss problems and deliver solutions. Successful policy and regulatory reform to improve the business environment require that the Government collaborates closely with the private sector. The success of SEBRAE and IPAs, such as INDI and Pólo-RS, may be attributable also to their composition and participation of the private sector. Moreover, the Government should be aware that business linkages can only be effective when companies recognize they have a potential vested interest in forging them.

Concerning possible strategies for Projeto Vínculos in Brazil, some current programs related to SMEs could be considered as potential strategies for strengthening linkages. One is the Local Productive Arrangements (LPA) Program. More than 500 potential LPAs have been identified in the country. Clusters to be supported should be selected due to their strong presence in the economy or because they are seen as strategic for future growth. The business incubator system is growing in Brazil, and some programs exist at the state and national level (e.g. SEBRAE Program for Business Incubators; National Program to Support Business Incubators). The Brazilian Association of Business Incubators and Science Parks (ANPROTEC) is among the strongest incubator/park associations in the world. Among the largest sponsors of incubators are federal agencies (52\%) and private organizations ( $40 \%$ of total). Brazilian companies that began operations under the wing of organizations like ANPROTEC showed a survival rate of $75 \%$ after their first three years of operation, while the national average is no more than $25 \%$. Those incubators have achieved outstanding success in bringing together start-up businesses and offering them technical support provided by an organization that is most often associated with a university, NGO or government office. Those programs may be targeted by projects or policies related to linkages in Brazil, given that the exchanges provided by entrepreneurs in the incubators create a rich environment for SMEs. Furthermore, the business environment is stimulated and enriched, since strong connections between the academic and research institutions and that of the business sector may be created.

Conflicts of interests may drive governments away from leading BL programs, as unveiling a company to governmental institutions may be seen with skepticism by the private sector, especially for companies with some kind of irregular status, which is not uncommon for a micro or small company in less developed areas. A third institution is more reliable for intermediate companies' and governments' interests: BDS providers may have more legitimacy to lead and operate a BL program. Also, although TNCs have technological know-how and administrative capacity, technological and managerial training are generally beyond their core business.

BL policies may be important complements to local industrial and development policies. For the states sheltering the most qualified companies, BL may be forged with a special focus on technology transfer, together with the industrial policy. 
This article has some constraints that should be taken into account in future research. Further quantitative research may consider the measurement of spillovers in BL programs, mainly in the Latin American context, where inequalities among regions still persist. Programs intended to foster BLs exclusively created and managed by large companies (as the PETROBRAS' Program for the Quality Assurance of Materials and Related Services, and BASF' Value Chain Development Program) were not considered in this article. Their effectiveness, spillovers and impact on the value chain lack understanding. Further research could also analyze the goals of companies funding programs of this nature; whether they are based on economic rationality, social responsibility, or both. While two kinds of programs (SDPs and Projeto Vínculos) were addressed, the organizational design was not considered, which could enable a deeper understanding of their operation, and ways to interact with the public sector.

This article evaluated the conditions needed, but not specific tactics, to develop public policies. Analyzing and proposing the design of public policies, under legal aspects, and their managerial impacts are essential in the field of BL and development. Additionally, the governance systems, both those comprising the relationship between companies and those dealing with the connection with the public sector, could be examined.

To conclude, the creation of TNC-SME linkages is, in fact, neither easy nor automatic. According to United Nations Conference on Trade and Development (2001), the single most important host country factor influencing linkage formation is the availability of local suppliers with competitive costs and quality. Local suppliers' development can be supported by special programs, but their competitiveness is also dependent on a favorable environment comprised of broader policy, economic, social and cultural aspects. Therefore, the overall government policy of the country matters, not only industrial policy.

The existing levels of host country technological and structural development will determine what types of linkages will be the most appropriate. Therefore, Brazil needs to identify the kinds of investments that are most likely to form the types of linkages best suited to the country's stage of development, and ensure that barriers to those types of linkages are minimized. In fact, linkage programs are never the same, and local conditions are distinct, which demands a comprehensive investigation of the specific situation a linkage program will confront. This is so that it can be designed to meet specific region needs and, consequently, promote development. This calls for a regional and sub-regional approach for a country the size of Brazil.

\section{Received 08 May 2009; received in revised form 15 October 2010.}

\section{Acknowlodgements}

The authors are grateful to Luciano Thomé e Castro (EAESP-FGV) for his insightful contribution.

\section{Note}

\footnotetext{
${ }^{1}$ The empirical research used as a basis for this article is an extension of the empirical research that was used as a basis for another article by the same authors: Bourguignon and Botelho (2009).
} 


\section{References}

Almeida, A., Cretoiu, G., Mendonça, G. D., Rossetti, J. P., \& Resende, P. T. V. (2007). The Brazilian case on international good practices on TMC-SME linkages. New York-Geneva: UNCTAD.

Banco Central do Brasil. (2010). 2009 statistics report. Brasília: Autor.

Battat, J., Frank, I., \& Shen, X. (1996). Suppliers to multinationals: linkages programs to strengthen local companies in developing countries. Washington, DC: Foreign Investment Advisory Service, The World Bank.

Bornstein, L. (2003). Management standards and development practice in the South African aid chain. Public Administration and Development, 23(5), 393-404. doi: 10.1002/pad.291

Bourguignon, M. F. B., \& Botelho, D. (2009). Vínculos de negócios entre grandes empresas compradoras e pequenos fornecedores locais: implicações para políticas públicas e desenvolvimento. Revista de Administração Pública, 43(6), 1407-1434. doi: 10.1590/S003476122009000600009

Dunning, J. H., \& Lundan, S. (2008). Institutions and the OLI paradigm of the multinational enterprise. Asia Pacific Journal of Management, 25(4), 573-593. doi: 10.1007/s10490-0079074-z

Fortanier, F. (2007). Foreign direct investment and host country economic growth: does the investor's country of origin play a role? Transnational Corporations, 16(2), 41-76.

Gefferi, G., Humphrey, J., \& Sturgeon, T. (2005). The governance of global value chains. Review of International Political Economy, 12(1), 78-104. doi: 10.1080/09692290500049805

Girma, S. G. H., \& Pisu, M. (2008). Exporting, linkages and productivity spillovers from foreign direct investment. Canadian Journal of Economics, 41(1), 320-340. doi: 10.1111/j.13652966.2008.00465.x

Giroud, A. (2006). Is Government support really worth it? Developing backward linkages in Malaysia. In A. Tavares \& A. C. T Aurora (Eds.), Multinationals, clusters and innovation: does public policy matter? (pp. 111-154). Basingstoke: Palgrave Macmillan.

Giroud, A. (2007a). Government policies towards FDI across East and Southeast Asia: a comparative review of business policies encouraging inter-firm relationships between TNCs and local firms'. In H. W.-C. Yeung (Ed.), Handbook on Research in Asian Business (Chap. 14, pp. 266-284). Edward Elgar: Cheltenham.

Giroud, A. (2007b). MNEs vertical linkages: the experience of Vietnam after Malaysia. International Business Review, 16(2), 159-176. doi: 10.1016/j.ibusrev.2006.11.003

Giroud, A., \& Botelho, D. (2008, March). Policies promoting MNEs linkages in host economies: a comparison between Brazil and Malaysia. Proceedings of the Organisation for Economic Cooperation and Development (OECD) Global Forum of Investment, Paris, France, 7.

Ivarsson, I., \& Alvstam, C. G. (2004). International technology transfer through local business linkages: the case of Volvo trucks and their domestic suppliers in India. Oxford Development Studies, 32(2), 241-260. doi: 10.1080/13600810410001699975

Jenkins, B., Akhalkatsi, A., Roberts, B., \& Gardiner A. (2007). Business linkages: lessons, opportunities and challenges. Cambridge: Harvard University Press. 
Jeppesen, S., \& Hansen, M. W. (2004). Environmental upgrading of third world enterprises through linkages to transnational corporations: theoretical perspectives and preliminary evidence. Business Strategy and Environment, 13(4), 261-274. doi: 10.1002/bse.410

Krause, D. R., Handfield, R. B., \& Tyler, B. B. (2007). The relationships between supplier development, commitment, social capital accumulation and performance improvement. Journal of Operations Management, 25(2), 528-545. doi: 10.1016/j.jom.2006.05.007

Kumar, S., \& Bergstrom, T. (2008). An exploratory study of the relations between the U.S. manufacturers and their local distributors in developing markets. Information Knowledge Systems Management, 7(3), 301-334.

Lall, S. (2002). Linking FDI, technology development for capacity building and strategic competitiveness. Transnational Corporations, 11(3), 39-88.

Lall, S., \& Narula, R. (2004). Foreign direct investment and its role in economic development: do we need a new research agenda. The European Journal of Development Research, 16(3), 447-464. doi: 10.1080/0957881042000266589

Meyer-Stamer, J. (2006, June). Good practices in the promotion of businesses linkages from an operational perspective: evidence from the field. Proceedings of the United Nations Conference on Trade and Development Expert Meeting, Geneva, Switzerland, 53.

Moran, T. H. (2006). Harnessing foreign direct investment: policies for developed and developing countries. Washington DC: Centre for Global Development.

Neves, M. F., Castro, L. T., \& Consoli, M. A. (2010). Marketing methods to improve company strategy. New York: Routledge.

Nogueira, C. (2001). Análise do discurso. In L. Almenida \& E. Fernandes (Eds.), Métodos e técnicas de avaliação: novos contributos para a prática e investigação (pp. 1-51). Braga: CEEP.

Observatório Social. (2005). Os investimentos das multinacionais no Brasil, panorama histórico, tendências recentes e o desafio do desenvolvimento com promoção de direitos. São Paulo: Autor.

Scott-Kennel, J. (2007). Foreign direct investment and local linkages: an empirical investigation. Management International Review, 47(1), 1-27.

Serviço Brasileiro de Apoio às Micro e Pequenas Empresas. (2008). Anuário do trabalho na micro e pequena empresa 2008. Brasília: Autor.

Shen, X. (2008). Linking local suppliers to multinationals: how can governments play a useful role? Washington: World Bank.

United Nations Conference on Trade and Development. (2001). World investment report 2001: promoting linkages. New York-Geneva: United Nations.

Yin, R. K. (2005). Case study research: design and methods. Los Angeles: Sage. 


\section{APPENDIX}

\section{Appendix 1}

\section{Interview Protocol}

\section{INDUSTRIAL MARKETING}

1. How would you describe the relationship with your clients? Is it cordial, friendly, cold?

2. How do you set prices for your clients?

3. How frequently do your clients buy your products?

4. On average, what is the product volume per transaction?

5. Which is the length of delivery time and payment terms? How do you negotiate both?

6. Do buyers impose any type of criteria or require any certification for you to be able to sell to them?

7. What do you expect from a buyer?

8. Does the firm participate in any other supplier development program?

\section{FIRMS’ RELATIONSHIPS}

9. How can your firms' products be classified in terms of value added level?

10. Is there exclusivity present for any of the relationships you have with buyers?

11. Are you an outsourced partner for a firm?

12. Is there anything in terms of costs and quality that could be improved if negotiated with buyers?

13. Are there relevant costs to strengthen the relationship with suppliers or clients? Of which type and who would be responsible for them?

14. How is quality evaluated by suppliers?

15. How can you describe product quality requirements?

16. Are there product specifications?

17. How are these requirements controlled?

18. Would you envision any type of necessary improvement in order to develop new markets? Of which type?

\section{SUPPLIER DEVELOPMENT PROGRAMS}

19. Describe your strategy to identify new clients?

20. Is there the intention to have a reduced number of partners or any specific number?

21. What were the expected benefits of supplier development programs?

22. Which expectations were met?

23. Is there any accomplishment that was not expected before hand?

\section{STARTING IN THE PROGRAM}

24. How did the company enter into the program? From where did the initiative come from? From the company itself, from a client)?

25. What is the company supposed to do in order to participate?

The questions below refer to the buyer.

We would like to know the relationship your company has with the following steps:

a. What is the main motivation your company has for enrolling in the program?

b. How were the program objectives set?

c. How was the program evaluation criteria established?

d. How was the program return measured?

e. How were the partners selected?

f. What does each of the partners do in the program?

g. Does your company really need a program to develop an action like this? 


\section{(Continued)}

\begin{tabular}{ll}
\hline & \multicolumn{1}{c}{ ARTICULATION OF PARTICIPATING COMPANIES } \\
\hline 26. & What is the relationship of your company with others participating in the program? \\
27. & What is the relevance to you of other companies' participation in the program? \\
28. & What are the main benefits perceived by your company? \\
29. & Which are the benefits for your clients? \\
30. & Was there any type of investment made by your company? \\
31. & How are other participating companies' costs are shared? \\
32. & Are there indicators for guiding the companies' participation in the program? \\
\hline & \\
\hline 33. & What are the most difficult aspects of the program? \\
34. & What are the easiest aspects of the program? \\
35. Can you say “there were good results from this program”? \\
36. $\quad$ What were the results so far? \\
37. Was knowledge generated that was not anticipated?
\end{tabular}

\section{RELATIONSHIP WITH THE GOVERNMENT}

38. How is the relationship of your company with the local government?

39. Are there governmental programs with which your company is somehow related? Any initiative that accesses public resources, projects funded by the government? Any program of Banco do Brasil, Caixa Econômica Federal or BNDES...?

40. What are the main positive aspects of such programs?

41. Where do you think there should be programs that don't yet exist?

42. Why doesn't your company participate more heavily in governmental programs?

43. Are there internal limitations?

44. Or are the limitations from the governmental sector?

\section{RESULTS MEASUREMENT}

45. What are the main expected results? So far, have you reached any of them?

46. Was any short or long-term indicator developed?

47. Did any participating company give feedback to you?

48. Have you ever measured any gain? What are the project performance indicators?

\section{OTHERS}

49. Transaction complexity - Is production complex to be done?

50. Codification ability- Are there manuals, product and procedures written processes?

51. Production capacity - How did the company change, considering the development program? 